\title{
The Author Reply: Major Difficulties in Pursuing Research on Offspring of Former "Comfort Women” in Korea
}

\author{
Jeewon Lee and Soyoung Irene Lee ${ }^{\bowtie}$ \\ Department of Psychiatry, Soonchunhyang University Bucheon Hospital, Bucheon, Republic of Korea
}

As Park reported, the previous article on the intergenerational transmission of trauma effects in offspring of former "comfort women" had many limitations. It was a preliminary study on only 6 children of the survivors. ${ }^{1}$ Although the results were significant since it first demonstrated the intergenerational transmission of trauma effects in offspring of former "comfort women," further studies on a larger sample are warranted. Since all the personal information of the survivors and their families are privately held by the Ministry of Gender Equality and Family, further studies on offspring of the survivors are feasible only with the support from the Ministry. However, to our knowledge, there are currently no specific plans or directions for further research on offspring of former "comfort women," probably due to many barriers. The 6 children of the former "comfort women" who had participated in the previous study was not a convenience sample. All the children of 38 survivors who had been alive in July 2016 were asked to participate in the study and only 6 children had given consent. Therefore, including children of the deceased former "comfort women" is the only way to expand the sample size.

However, there are many practical difficulties in pursuing research on children of the deceased survivors. First, even if the biological children of the deceased former "comfort women" are included, the sample size would not be a large number. The total number of registered survivors are 240, but many are reported to be unmarried or impotent. ${ }^{2}$ Second, given the high rate of refusal in the former study, it would be very hard to gain consent from the children of the deceased survivors as well. Many of them could still suffer from stigma

Received: May 10, 2019 Accepted: May 13, 2019

$\triangle$ Correspondence: Soyoung Irene Lee, MD, PhD

Department of Psychiatry, Soonchunhyang University Bucheon Hospital, 170 Jomaru-ro, Bucheon 14584, Republic of Korea

Tel: +82-32-621-5063, Fax: +82-32-621-6950

E-mail: irenelee@schmc.ac.kr

(a) This is an Open Access article distributed under the terms of the Creative Commons Attribution Non-Commercial License (https://creativecommons.org/licenses/by$\mathrm{nc} / 4.0$ ) which permits unrestricted non-commercial use, distribution, and reproduction in any medium, provided the original work is properly cited. and be reluctant to be exposed as children of former "comfort women." Third, maternal PTSD status and other maternal trauma-related information would be lacking which is very important in evaluating transmitted effects of trauma. In the previous study, we were only able to evaluate the maternal PTSD diagnosis due to the limited information of the survivors on the specific age or duration of the trauma. In the children of the deceased survivors, information of the mothers related to the trauma would be even more limited.

The largest body of research on transgenerational transmission of trauma has been the studies on second and third generation of Holocaust survivors. ${ }^{3}$ Many studies have demonstrated that children and even grandchildren of Holocaust survivors with PTSD often exhibit psychiatric problems including anxiety, guilt, aggressive behaviors and more. ${ }^{4}$ The studies on offspring of Holocaust survivors have enlightened the effects of transmitted trauma and the epigenetic modifications. Recently, many studies have been conducted on children of responders of 9/11 World Trade Center (WTC) attack. ${ }^{5}$ The results showed that children of WTC responders have increased risk for behavioral difficulties, poor school functioning, and emotional symptoms. ${ }^{6}$ These studies would not have been possible without the special interest and support from the government and the society.

Therefore, the Korean government should take the initiative in conducting further research on offspring of former "comfort women" despite the many methodological difficulties and limitations the research would face. Only 21 "comfort women" survivors are currently alive. The number of survivors is decreasing every moment now. Finding evidence of effects of trauma in descendants of former "comfort women" is very important in order to demonstrate that the trauma is an ongoing tragedy even if decades have passed and even if most of the victims have passed away. Also, it could provide grounds for the need for reparation for the families of the survivors as well. Furthermore, improved understanding of epi- 
genetic transmission of PTSD in children of trauma survivors would allow better prevention and more targeted treatment interventions.

\section{Acknowledgments}

This study was supported by Soonchunhyang University Research Fund.

\section{Conflicts of Interest}

The authors have no potential conflicts of interest to disclose.

\section{ORCID iD}

$\begin{array}{ll}\text { Soyoung Irene Lee } & \mathrm{https} / / / \text { orcid.org/0000-0003-2473-2954 } \\ \text { Jeewon Lee } & \text { https://orcid.org/0000-0001-5930-1834 }\end{array}$

\section{REFERENCES}

1. Lee J, Kwak YS, Kim YJ, Kim EJ, Park EJ, Shin Y, et al. Transgenerational transmission of trauma: psychiatric evaluation of offspring of for- mer "comfort women," survivors of the Japanese military sexual slavery during World War II. Psychiatry Investig 2019;16:249-253.

2. Lee J, Kwak YS, Kim YJ, Kim EJ, Park EJ, Shin Y, et al. Psychiatric sequelae of former "comfort women," survivors of the Japanese military sexual slavery during World War II. Psychiatry Investig 2018;15:336-343.

3. Fossion P, Leys C, Vandeleur C, Kempenaers C, Braun S, Verbanck P, et al. Transgenerational transmission of trauma in families of Holocaust survivors: the consequences of extreme family functioning on resilience, sense of coherence, anxiety and depression. J Affective Disord 2015;171: 48-53.

4. Kellermann NP. Epigenetic transmission of holocaust trauma: can nightmares be inherited. Isr J Psychiatry Relat Sci 2013;50:33-39.

5. Gargano LM, Dechen T, Cone JE, Stellman SD, Brackbill RM. Psychological distress in parents and school-functioning of adolescents: results from the World Trade Center Registry. J Urban Health 2017;94:597-605.

6. Uchida M, Feng H, Feder A, Mota N, Schechter CB, Woodworth HD, et al. Parental posttraumatic stress and child behavioral problems in world trade center responders. Am J Ind Med 2018;61:504-514. 